\title{
Mucosal Schwann Cell Hamartoma-Colonic Lesion Susceptible to an Interesting Differential Diagnosis
}

\author{
J. Ortiz , L. Chinchilla, E. Muñoz, Md Ludeña \\ Department of Pathological Anatomy of the University Hospital of Salamanca, Salamanca, Spain \\ Email: *jortiz@usal.es
}

How to cite this paper: Ortiz, J., Chinchilla, L., Muñoz, E. and Ludeña, Md. (2018) Mucosal Schwann Cell Hamartoma-Colonic Lesion Susceptible to an Interesting Differential Diagnosis. Open Journal of Pathology, 8, 101-105.

https://doi.org/10.4236/ojpathology.2018.83012

Received: May 20, 2018

Accepted: July 15, 2018

Published: July 18, 2018

Copyright $\odot 2018$ by authors and Scientific Research Publishing Inc. This work is licensed under the Creative Commons Attribution International License (CC BY 4.0).

http://creativecommons.org/licenses/by/4.0/

\begin{abstract}
We present a mucosal Schwann cell hamartoma that was observed in a 63-year-old woman with no personal or family history of interest who underwent a screening colonoscopy for early detection of colon cancer. During colonoscopy, a small polyp with a maximum diameter of $0.8 \mathrm{~cm}$ was detected at the rectosigmoid level. Histologically, a benign lesion of neuroid aspect was observed, consisting of multiple spindle cell fascicles that was positive for S-100 and negative for enolase, synaptophysin, CD34, CD117, actin, desmin, Dog1, EMA, and neurofilaments. These findings, supported by the family and personal history of the patient, allowed us to make a diagnosis, discarding other entities.
\end{abstract}

\section{Keywords}

Schwann Cell Hamartoma, Immunohistochemistry

\section{Introduction}

The remarkable advancements in exploratory and diagnostic techniques have increased our meticulous and precise knowledge of the different lesions encountered in daily health care work, and this know-how has led to considerable improvements in diagnostic and therapeutic quality.

This statement, which is applicable to all clinical specialties, pertains equally to histopathology, a branch of medicine in which immunohistochemistry plays a fundamental role, allowing us to understand more deeply parameters related to the diagnosis, histogenesis, prognosis, and treatment of a given process.

We think that this context is relevant to the case presented below, a mucosal Schwann cell hamartoma, and a rare lesion predominantly affecting the colon described in 2009 by Gibson and Hornick [1] in a series of 26 cases. These au- 
thors concluded that they were facing a new neuroid entity different from neuromas, Schwannomas or perineuriomas, such theory being confirmed by later work.

Everything described above, together with our interest in research and scientific dissemination, have encouraged us to present this case.

\section{Clinical Case}

A 63-year-old woman with no relevant medical history underwent a colonoscopy after presenting occult blood in the stool. Colonoscopy revealed a sessile polypoid lesion with a maximum diameter of $0.8 \mathrm{~cm}$ at the level of the rectosigmoid junction, and the lesion was excised during the exploratory act. Histological study showed a lesion limited to the lamina propria that respected the superficial colonic epithelium, its proliferative character and type, formed by multiple fascicles of fusiform cells (Figure 1 and Figure 2). This lesion was cytologically benign and positive for S-100 (Figure 3) and vimentin but negative for cytokeratins, actin,

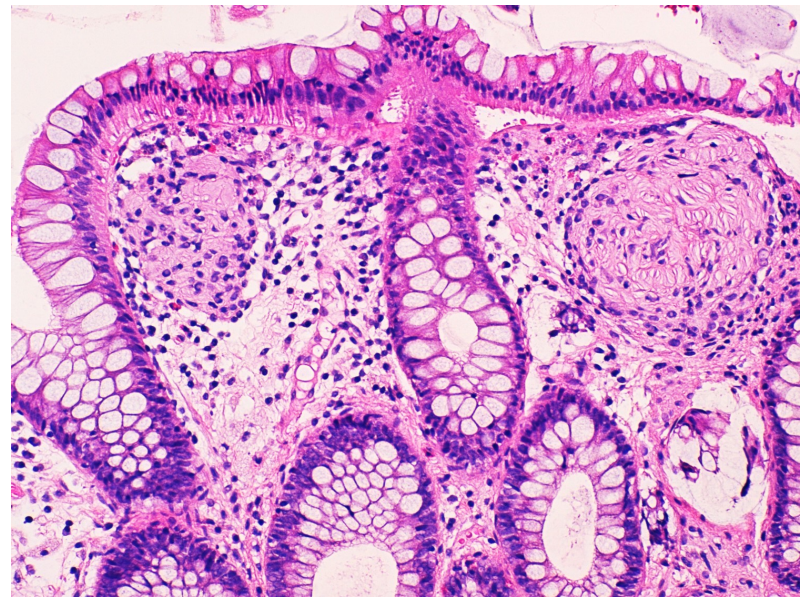

Figure 1. Schwann cell hamartoma: Nodular lesions of neuroid type located below respected colonic epithelium $(\mathrm{HE} \times 200)$.

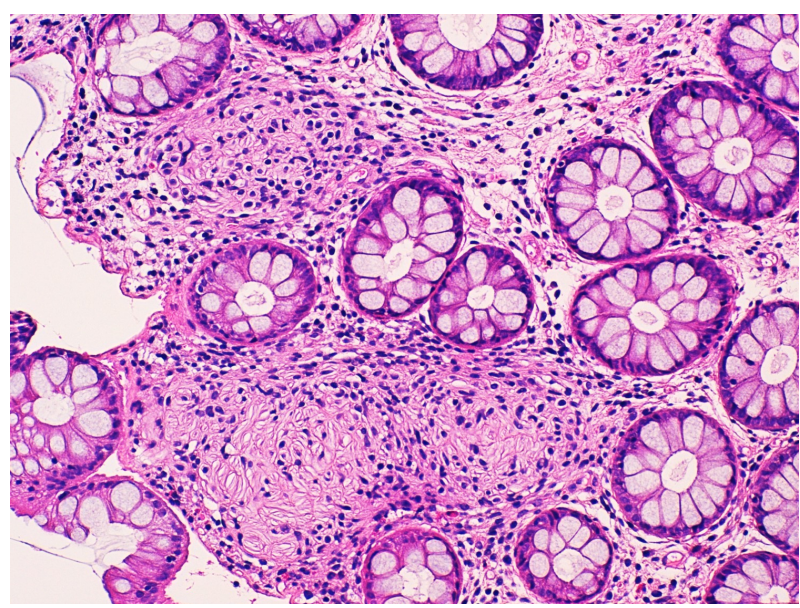

Figure 2. Schwann cell hamartoma: Neuroid cell accumulations both nodular and plexiform in appearance $(\mathrm{HE} \times 200)$. 


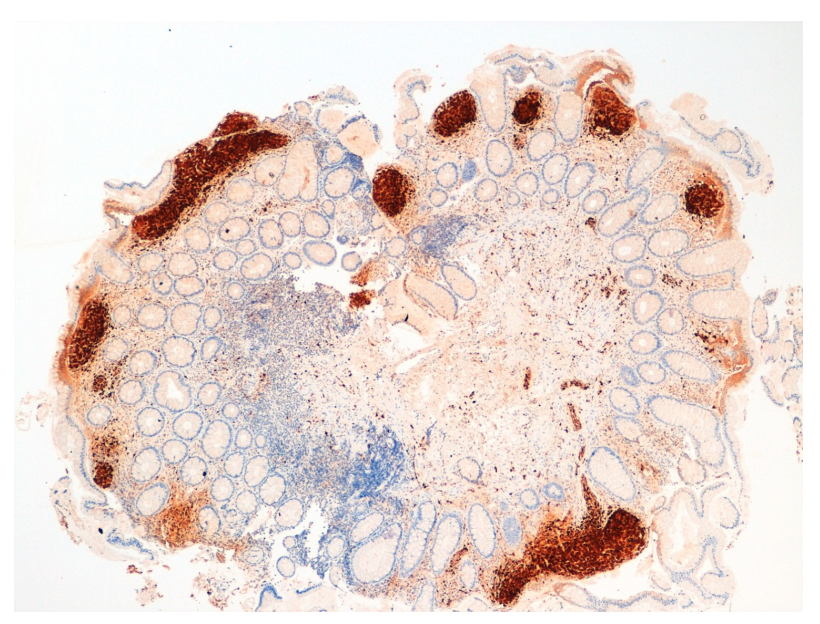

Figure 3. Positivity of the lesion for S-100 (Immuno $\times 40$ ).

desmin, CD34, CD117, Dog1, neurofilaments, enolase, EMA, CD68, and synaptophysin. Its proliferative index (MIB-1) was less than $1 \%$.

These findings, which were confirmed by the absence of a personal and family history of interest, led us to the diagnosis of Schwann cell colonic hamartoma.

\section{Discussion}

The fusiform cell fascicles of benign appearance showed a clearly neuroid pattern, supported by immunohistochemistry (positivity for S-100 and negativity for other neuronal and peripheral nerve markers), constitute the two basic pillars to support the diagnosis of mucosal Schwann cell hamartoma, a colonic lesion is recently described [1] [2] [3]. This rare entity has been reported in the medical literature on very limited occasions [4]. From the clinical perspective it affects the descending colon and rectosigmoid region, presenting as a solitary polypoid lesion, sometimes associated with ulcerative colitis [5] [6]. Despite its benign appearance, the interest of this pathology lies in its differential diagnosis that allows the elimination of processes such as neurofibroma, ganglioneuroma, ganglioneuromatosis, or mucosal neuroma, which are related to familial and hereditary diseases such as Recklinghausen NF1, MEN 2B, or Cowden syndrome [7] [8] [9] [10].

Of uncertain etiology, to determine the nature of this entity, benign and non-hereditary, to which some authors grant a reparative nature, and to offer an exciting field of research, all the more so if we take into account the recent description of some cases of extracolonic location [11] [12].

In our patient, we describe an illustrative example of a Schwann cell hamartoma that logically demanded a wide differential diagnosis. Its typical histology suggested the diagnosis, allowing us to rule out the possibility of a schwannoma (encapsulated lesion, larger and with involvement of the submucosa) or a granular cell tumor, while immunohistochemistry allowed us to rule out entities such as mucosal neuroma (EMA+, neurofilament+), neurofibroma (EMA+, $\mathrm{CD} 34+$, neurofilaments+), ganglioneuroma and ganglioneuromatosis (enolase+ 
synaptophysin+, neurofilaments+), perineurioma (S-100-, EMA+), or GIST (CD34+Dog1+, CD117+) [13] [14] [15].

Similarly, it should be noted that the benign aspect of the lesion was confirmed by its clinical evolution, since about four years after its diagnosis the patient does well without signs of recurrence.

Finally, we would like to again highlight the importance of clinical-pathological collaboration, since adequate clinical information (allowing us to discard personal or family antecedents for such pathology) provided us with a valuable element to ratify our diagnosis in the present case.

\section{Consent}

Written informed consent was obtained from the patient for publication of this case report and any accompanying images.

\section{References}

[1] Gibson, J.A. and Hornick, J.L. (2009) Mucosal Schwann Cell "Hamartoma”: Clinicopathologic Study of 26 Neural Colorectal Polyps Distinct from Neurofibromas and Mucosal Neuromas. The American Journal of Surgical Pathology, 33, 781-787. https://doi.org/10.1097/PAS.0b013e31818dd6ca

[2] Pasquini, P., Baiocchini, A., Falasca, L., Annibali, D., Gimbo, G., Pace, F. and Del Nonno, F. (2009) Mucosal Schwann Cell "Hamartoma": A New Entity? World Journal of Gastroenterology, 15, 2287-2289. https://doi.org/10.3748/wjg.15.2287

[3] Rocco, E.G., Iannuzzi, F., Dell'Era, A., Falleni, M., Moneghini, L., Di Nuovo, F., Braidotti, P., Bulfamante, G. and Romagnoli, S. (2011) Schwann Cell Hamartoma: Case Report. BMC Gastroenterology, 11, 68. https://doi.org/10.1186/1471-230X-11-68

[4] García-Molina, F., Ruíz-Macia, J.A. and Sola, J. (2018) Mucosal Schwann Cells Hamartoma: Review of a Recently Described Entity. Revista Española de Patología, 51, 49-54. https://doi.org/10.1016/j.patol.2017.03.003

[5] Neis, B., Hart, P., Chandran, V. and Kane, S. (2013) Mucosal Schwann Cell Hamartoma of the Colon in a Patient with Ulcerative Colitis. Gastroenterology and Hepatology, 9, 183-185.

[6] van Deen, W.K. and Hommes, D.W. (2013) Mucosal Schwann Cell Hamartoma in Ulcerative Colitis: Diagnosis and Clinical Relevance. Gastroenterology and Hepatology, 9, 185-186.

[7] Bilal, M., Bilimoria, F. and Clarke, K. (2016) An Isolated Colonic Neurofibroma. Annals of Gastroenterology, 29, 381. https://doi.org/10.20524/aog.2016.0029

[8] Ofori, E., Ona, M., Ramai, D., Huang, T., Xiao, P. and Reddy, M. (2017) Colonic Ganglioneuroma: A Rare Finding during Colorectal Cancer Screening. Case Reports in Gastroenterology, 11, 434-439. https://doi.org/10.1159/000477716

[9] Matthews, M.A., Adler, B.H., Arnold, M.A., Kumar, S., Carvalho, R. and Besner, G.E. (2013) Diffuse Intestinal Ganglioneuromatosis in a Child. Journal of Pediatric Surgery, 48, 1129-1133. https://doi.org/10.1016/j.jpedsurg.2013.03.066

[10] McClurg, S.W., Wakely Jr., P.E. and Chio, E.G. (2015) Laryngeal Neuromas in a Case of Multiple Endocrine Neoplasia Type 2B. Ear, Nose, \& Throat Journal, 94, E20-2. 
[11] Hytiroglou, P., Petrakis, G. and Tsimoyiannis, E.C. (2016) Mucosal Schwann Cell Hamartoma Can Occur in the Stomach and Must Be Distinguished from Other Spindle Cell Lesions. Pathology International, 66, 242-243. https://doi.org/10.1111/pin.12376

[12] Khanna, G., Ghosh, S., Barwad, A., Yadav, R. and Das, P. (2018) Mucosal Schwann Cell Hamartoma of Gall Bladder: A Novel Observation. Pathology, 50, 480-482. https://doi.org/10.1016/j.pathol.2017.11.095

[13] Cangiarella, J., Jagirdar, J., Adelman, H., Budzilovich, G. and Greco, M.A. (1993) Mucosal Neuromas and Plexiform Neurofibromas: An Immunocytochemical Study. Pediatric Pathology, 13, 281-288. https://doi.org/10.3109/15513819309048214

[14] Hechtman, J.F. and Harpaz, N. (2015) Neurogenic Polyps of the Gastrointestinal Tract: A Clinicopathologic Review with Emphasis on Differential Diagnosis and Syndromic Associations. Archives of Pathology \& Laboratory Medicine, 139, 133-139. https://doi.org/10.5858/arpa.2013-0431-RS

[15] van Wyk, A.C., van Zyl, H. and Rigby, J. (2018) Colonic Perineurioma (Benign Fibroblastic Polyp): Case Report and Review of the Literature. Diagnostic Pathology, 13, 16. https://doi.org/10.1186/s13000-018-0694-Z 